\title{
Simulations of human-induced floor vibrations considering walking overlap
}

\author{
Yuanzhi Cai ${ }^{1} \cdot$ Guobin Gong ${ }^{1}\left[\right.$. Jun Xia ${ }^{1}$ Jiale $\mathrm{He}^{2} \cdot$ Jianli Hao ${ }^{1}$
}

Received: 1 October 2019 / Accepted: 28 November 2019 / Published online: 4 December 2019

(c) Springer Nature Switzerland AG 2019

\begin{abstract}
Floor vibration induced by human activities has become an important concern to both designers and developers, especially for modern structures designed with larger spans and lower weights. However, there is currently no systematic approach in codes of practices to assessing floor vibration, and the load models induced by human walking are usually oversimplified by ignoring overlapping between successive footfalls. This paper addresses those shortcomings by conducting a series of finite element simulations of three slabs with different thicknesses subjected to dynamic loads induced by human walking activities. A total of six load models ranging from the most realistic to the most simplified were used for the simulations. The simulation results show that the overlapping time between successive footfalls has a significant impact on human-induced vibration for floors with thicknesses of 100-200 $\mathrm{mm}$. The results also indicate that the critical walking frequency should be shifted to a higher value than the resonant frequency, to allow for the humaninduced load increasing with walking frequency.
\end{abstract}

Keywords Finite element method · Human-induced vibration · Serviceability limit state · Simulation · Fundamental frequency Walking frequency Walking overlap

\section{Introduction}

Over the last several decades, the development of analysis software and construction materials has resulted in a trend towards more slender and long-span structures, characterised by low fundamental frequencies and damping ratios, and consequently more sensitive to vibration problems $[12,26,28,32,41]$. People exposed to an excessive vibration environment tend to have uncomfortable feelings, which particularly affects the serviceability of buildings such as hospitals, factories and laboratories where vibration-sensitive machines/apparatus is involved. Therefore, serviceability limit state (SLS) criteria, particularly the vibration serviceability of floors induced by human activity, may increasingly govern the design $[1,6,21,23]$. Failure to recognise this vibration problem has led to a number of disastrous incidents, such as the temporary closures of the London Millennium Bridge on its opening day in 2000, due to excessive human-induced lateral vibration [12].

The nature of floor vibration due to human activity is consistent with the well-established theory of structural dynamics. Specifically, when the natural frequency of a floor is significantly higher than the walking frequency, human-induced excitation would behave like a series of impulses as the response is governed by transient responses. However, when a walking frequency is close to the natural frequency of the floor, the vibration caused by a single footfall could be further magnified by the following footfall. In other words, the vibration would build up over time, especially when the floor's natural frequency is

Guobin Gong, Guobin.Gong@xjtlu.edu.cn; Yuanzhi Cai, ycai4321@uni.sydney.edu.au; Jun Xia, Jun.Xia@xjtlu.edu.cn; Jiale He, Jiale.He13@student.xjtlu.edu.cn; Jianli Hao, Jianli.Hao@xjtlu.edu.cn | ${ }^{1}$ Department of Civil Engineering, Xi'an Jiaotong-Liverpool University, Suzhou, China. ${ }^{2}$ School of Civil Engineering and Transportation, South China University of Technology, Guangzhou, China. 
an integral of the walking frequency [38]. This phenomenon is known as resonance. Although the vibration of a slab could be analysed based on the differential by Eq. (1) shown below [34], enormous computational effort and complexity leave this equation impracticable to solve, since the loads vary in both time and space. Hence, this type of problem is usually solved using numerical methods, such as the Finite Element Method (FEM).

$$
\begin{aligned}
& D\left[\frac{\partial^{4} w(x, y, t)}{\partial x^{4}}+2 \frac{\partial^{4} w(x, y, t)}{\partial x^{2} \partial y^{2}}+\frac{\partial^{4} w(x, y, t)}{\partial y^{4}}\right] \\
& +\mu \frac{\partial^{2} w(x, y, t)}{\partial t^{2}}=p(x, y, t)
\end{aligned}
$$

where $D$ is the bending rigidity of the slab; $w(x, y, t)$ is the vertical deflection of the slab at point with coordinates $x$, $y$, and time $t ; \mu$ is mass per unit area of the slab; $p(x, y, t)$ is the external load acting on the slab.

Numerous comprehensive tests have been conducted to provide a better understanding of the dynamic performance of different floor systems [2, 11, 14, 15, 29], but there is no unified numerical simulation model pertinent to human-induced floor vibration. Most studies on the simulation of human-induced vibration use simplified load models, which may not represent realistic situations. For example, one frequently used load model proposed by da Silva et al. [11] and Figueiredo et al. [15], does not consider the overlap and the lateral distance between successive footfalls, which might lead to unconservative results. Therefore, the main objective of this paper is to explore the differences between several load models and to identify the most suitable one.

There are several different design criteria available to assess the serviceability problem of vibration, such as the lower boundary of the floor's fundamental frequency GB50010-2010 [17]; limitation on the maximum acceleration value AISC/CISC [3] and NBCC [31]; Root Mean Square (RMS) of acceleration ISO 2631-1 [25], ISO 10137:2007 [24] and VDI 2057-1 [24, 39]; and Vibration Dose Value BS 6472 [9]. It should be noted that although floor vibrations and comfort levels have been taken into consideration in some design guidelines in some countries, different criteria are used and there is no systematic standard or code of practice to quantify the influence of floor vibration to human walking. However, as the vibration perception descriptor, the RMS acceleration is more often selected by many guidelines, since it is relatively simple to calculate. Therefore, the RMS acceleration is adopted in this study to quantify floor vibration, which can be calculated as follows:
$\operatorname{RMS}(a)=\sqrt{\frac{1}{t_{2}-t_{1}} \int_{t_{1}}^{t_{2}} a^{2}(t) d t}$

where RMS $(a)$ is the RMS acceleration; $a(t)$ is the time history of acceleration; $t_{1}$ and $t_{2}$ define the beginning and the end of the time interval to be considered.

It should be mentioned that the value of RMS depends on the time period/interval chosen. There is some argument regarding what period should be chosen for the calculation of RMS accelerations. For example, Rasmussen [35] recommended a 1-60 s time period to calculate the RMS acceleration; ISO 2631-1 [25] and ISO 10137:2007 [24] suggested $1 \mathrm{~s}$ for this evaluation of vibration; the whole duration of the measurement was used in VDI 2057-1 [25, 39] and Pavic [33] proposed $10 \mathrm{~s}$ as the integration time interval. It is clear that there is no consensus in the integration time interval. However, it is natural to use the total analysis time duration in this study to ensure consistency of results.

\section{Human-induced dynamic loads}

In order to carry out dynamic analysis to assess the structural behaviour of the floor system, the characteristic of a single footfall load should first be defined. The walking force induced by a single pedestrian has been studied by many researchers. In general, human-induced dynamic loads have three components: in vertical, horizontallongitudinal, and horizontal-lateral. However, to investigate footfall induced vibration of floors, only the vertical component of the loads is interesting as it has the highest magnitude and floor systems are relatively flexible in the vertical direction. Therefore, "pedestrian-induced loads" in this study indicates vertical components.

Early research on the measurement of pedestrianinduced loads was reported by Harper et al. [19] and Harper [20], who found that the vertical load from a single footfall has a general shape similar to the letter " $M$ ", as shown in Fig. 1. This general shape has since been validated by a large number of comprehensive studies, e.g., Galbraith and Barton [16], Blanchard et al. [8], and Sedlacek et al. [36].

The above diagram can be interpreted as follows: the beginning of the curve $(A)$ reflects the initial contact between foot and ground; the first peak (B) is caused 


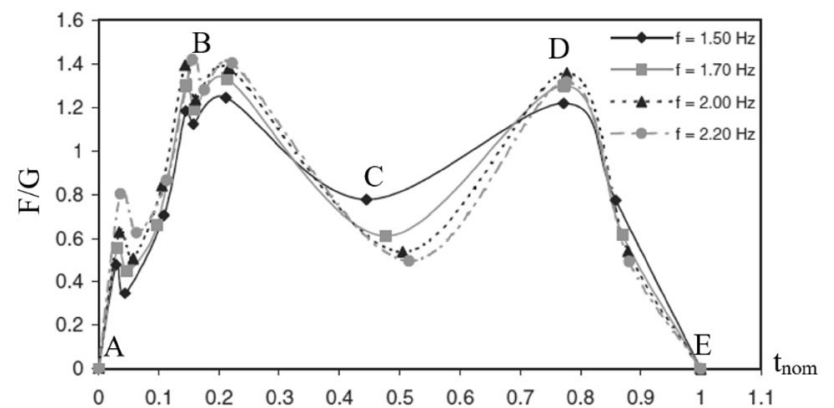

Fig. 1 Normalised single footfall load histories [36]

by self-weight of the person plus the additional inertial component due to the walking activity; trough (C) is because the part of the bodyweight is transferred to the other leg during the walking; the second peak represents the action of pushing off from the ground; finally point $(D)$ is where the whole foot has left the ground.

All the relevant studies have found that increasing walking frequency would result in increasing peak load magnitude, walking speed, and step length, which shows the complexity of human-induced loads. Fortunately, equations for the relationship between the aforementioned parameters have been found and adopted in many design guidelines, including this study. For example, the duration of one step suggested by Sedlacek et al. [36] is as follows:

$t_{s}=-0.515 f_{s}^{3}+3.2242 f_{s}^{2}-6.9773 f_{s}+5.8531$

where $t_{s}$ is the duration of the single footfall (in second); $f_{s}$ is the walking frequency (in $\mathrm{Hz}$ ).

Also, one of the most widely adopted relationships between walking frequency and velocity proposed by Bachmann and Ammann [6] is:

$v=1.67 f_{s}^{2}-4.83 f_{s}+4.5$

where $v$ is the velocity of walking (in $\mathrm{m} / \mathrm{s}$ ); $f_{s}$ is the walking frequency (in $\mathrm{Hz}$ ).

To be suitable for analysis, measured human-induced loads should be modelled analytically. In previous literature, there are mainly two types of load models, i.e. frequency domain models [18] and time-domain models. As time-domain models are more common for simulations, and due to their simplicity for programming implementation in ANSYS software, a time-domain force model by Sedlacek et al. [36] was selected for this study. In this approach, the force induced by a single footfall can be described by a polynomial of 8th order as Eq. (5) shows. The results are plotted in Fig. 2.

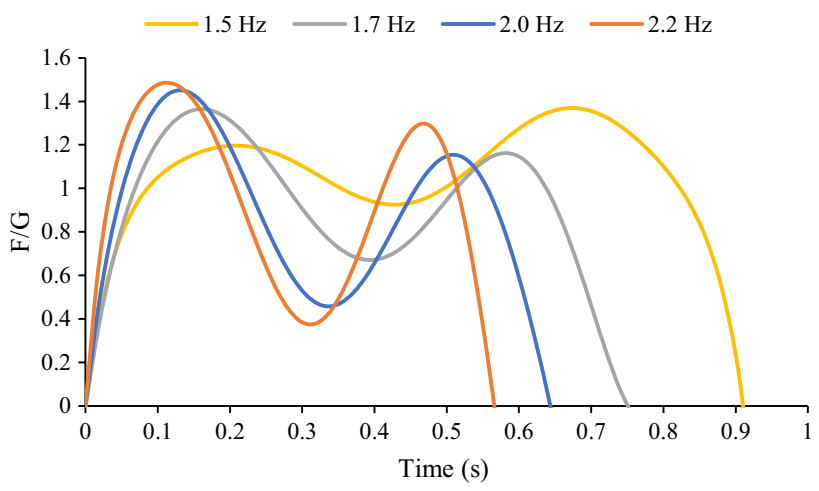

Fig. 2 Characteristic load time histories determined by Sedlacek et al. [36]. F/G is the ratio between footfall force and the self-weight of people; Time is the duration of one footfall (in second)

$F(t)=746\left(K_{1} t+K_{2} t^{2}+K_{3} t^{3}+K_{4} t^{4}+K_{5} t^{5}+K_{6} t^{6}+K_{7} t^{7}+K_{8} t^{8}\right)$

where $t$ is time within a single footfall (in second); $F(t)$ is the force induced by a single footfall (in Newton); $K_{i}$ are coefficients enumerated in Table 1.

Although the polynomial form expression is selected for analysis in this study, for discussion purposes, it should be noted that the human-induced loads could also be represented by the Fourier series and the Fourier's coefficient decreases with harmonic increase.

$F(t)=G+\sum_{i=1}^{n} G \alpha_{i} \sin \left(2 \pi i f_{s} t-\phi_{i}\right)$

where $F(t)$ is the force induced by a single footfall (in Newton); $G$ is the weight of people (in Newton); $i$ is the harmonic number; $n$ is the total number of contributing harmonics; $\alpha_{i}$ the Fourier's coefficient of the ith harmonic; $f_{s}$ is the walking frequency (in $\mathrm{Hz}$ ); $\phi_{i}$ is the phase of the $i$ th harmonic; $t$ is time within a single footfall (in second).

\section{Guidance for floor vibration serviceability assessment}

Based on the aforementioned serviceability criteria, there are currently two sources of guidance related to the issues of floor vibration serviceability. One is the AISC Design Guide [3], the other is the SCI Design Guide (2009).

\subsection{AISC design guide}

For North America, the AISC Design Guide is usually used for floor vibration design. The background of the AISC Design Guide can be found in Allen and Murray's 
Table 1 Coefficients $K_{i}$ dependent on walking frequency $f_{s}[36]$

\begin{tabular}{llll}
\hline & $f_{s} \leq 1.75 \mathrm{~Hz}$ & $1.75 \mathrm{~Hz} \leq f_{s} \leq 2.00 \mathrm{~Hz}$ & $2.00 \mathrm{~Hz} \leq f_{s}$ \\
\hline$K_{1}$ & $-8 \cdot f_{s}+38$ & $24 \cdot f_{s}-18$ & $75 \cdot f_{s}-120$ \\
$K_{2}$ & $376 \cdot f_{s}-844$ & $-404 \cdot f_{s}+521$ & $-1720 \cdot f_{s}+3153$ \\
$K_{3}$ & $-2804 \cdot f_{s}+6025$ & $4224 \cdot f_{s}-6274$ & $17,055 \cdot f_{s}-31,936$ \\
$K_{4}$ & $6308 \cdot f_{s}-16,573$ & $-29,144 \cdot f_{s}+45,468$ & $-94,265 \cdot f_{s}+175,710$ \\
$K_{5}$ & $1732 \cdot f_{s}+13,619$ & $109,976 \cdot f_{s}-175,808$ & $298,940 \cdot f_{s}-553,736$ \\
$K_{6}$ & $-24,648 \cdot f_{s}+16,045$ & $-217,424 \cdot f_{s}+353,403$ & $-529,390 \cdot f_{s}+977,335$ \\
$K_{7}$ & $31,836 \cdot f_{s}-33,614$ & $212,776 \cdot f_{s}-350,259$ & $481,665 \cdot f_{s}-888,073$ \\
$K_{8}$ & $-12,948 \cdot f_{s}+15,532$ & $-81,572 \cdot f_{s}+135,624$ & $-174,265 \cdot f_{s}+321,008$ \\
\hline
\end{tabular}

[4] research, with more detailed information and commentaries found in papers by Avci [5] and Barrett [7]. There are three components in the AISC Design Guide: design guidance regarding walking excitation, rhythmic excitation, and sensitive equipment. The design guide for walking excitation is dedicated to the prediction for the fundamental frequency of the bay with the peak acceleration response at a steady state, which is useful for a wide range of floor vibration serviceability problems. The prediction of the fundamental frequency in the AISC Design Guide is based on the classical structural dynamics theory and Dunkerley's equation [43]. Where Dunkerley's equation predicts the fundamental frequency for the Multi-Degree-of-Freedom (MODF) system by the following equation:

$\frac{1}{\omega^{2}} \approx \frac{1}{\omega_{1}^{2}}+\frac{1}{\omega_{2}^{2}}+\cdots+\frac{1}{\omega_{n}^{2}}$

where $\omega$ is the fundamental frequency of the whole system, and $\omega_{n}$ is the fundamental frequency considering the system as Single-Degree-of-Freedom (SODF) by ignoring all other masses. The prediction of the peak acceleration in the AISC Design Guide (1992) uses the simplified SDOF system for the bay under consideration. A four-term Fourier series is adopted to represent the human-induced dynamic loads. The effective mass of the simplified SDOF system is estimated by the theory of orthotropic plate equations. Finally, the dynamic response of the floor is taken at the mid-bay.

\section{2 $\mathrm{SCl}$ design guide}

The SCI Design Guide (2009) is usually used for floor vibration design in European countries. There are two approaches included in the SCI Design Guide (2009). One is the "Simplified Assessment for Steel Floors", which is applicable for hand calculations, the other one is the "General Assessment of Establishing Vibration Response", which is suitable for more advanced finite element analysis.

The first approach is similar to the AISC Design Guide. It focuses on the prediction for the fundamental frequency and acceleration response for the floor system, subjected to human excitation, especially for light-steel floor systems. As to the fundamental frequency estimation, the lower frequency of Mode A secondary beam mode and Mode $B$ primary beam mode is used. The schematic diagram for those modes is shown in Fig. 3.

Mode $A$ assumes a condition consisting of fixed slab ends, simply supported secondary beams, and rigid girders, while Mode B assumes a condition consisting of fixed slab ends, fixed secondary beams ends, and pinned primary beams. The fundamental frequency estimated by the SCI Design Guide has proved to be more accurate than the
Fig. 3 Mode of vibration used in SCI Design Guide (2009)

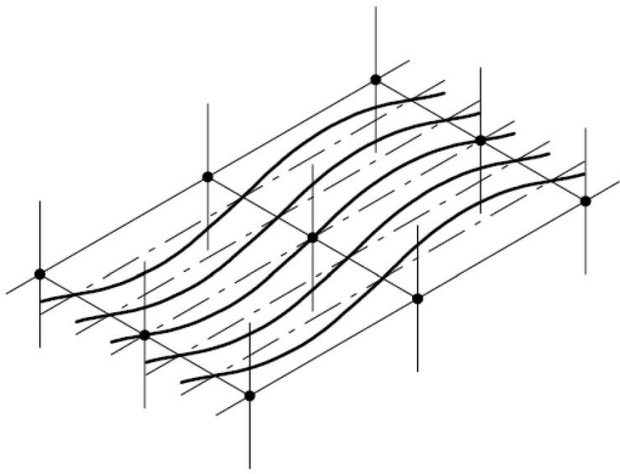

Mode A Secondary beam mode

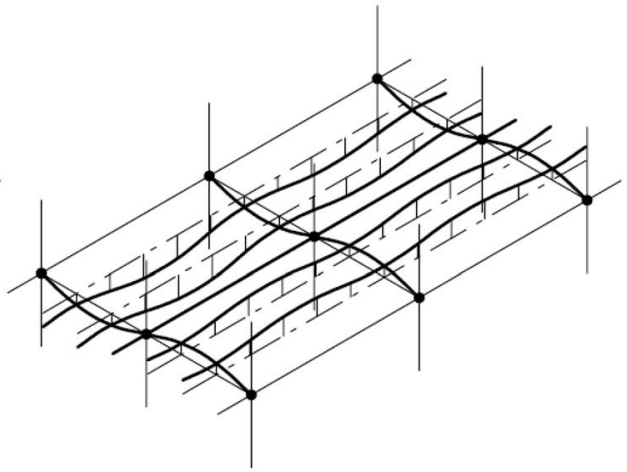

Mode B Primary beam mode

SN Applied Sciences 
AISC Design Guide by many researchers [13, 22, 30]. For the acceleration response, the effective mass is calculated following the same theory used in the AISC Design Guide. The proposed equation for acceleration prediction in the $\mathrm{SCI}$ Design Guide includes the following parameters: the dynamic amplification factor depending on the walking speed, the length of the walking path, the mode shape amplitudes at the place where the load is applied, and the response location of interest. However, different from the AISC Design Guide, RMS acceleration is adopted in the $\mathrm{SCI}$ Design Guide to quantify the acceleration response.

The second approach "General Assessment of Establishing Vibration Response" is based on the method proposed by Willford et al. [40] and Young [42], which is a frequency domain criterion of vibration serviceability specifically suitable for finite element programs. In their research, an enormous amount of footfall force was measured and the design value assigned as $75 \%$ of the fractile value of the statistical distribution. Multiple modes are required to be considered in this method, which should yield more accurate results compared to the simplified SDOF system used by some other methods.

\subsection{Difference between predictions by design guides and experimental results}

Many comparisons between predicted response and experimental results have been reported. A comparison between experimental natural frequencies and peak acceleration with the prediction of the AISC Design Guide was conducted by Sladki [37]. The results show that the AISC Design Guide (1992) can provide a reliable prediction for natural frequency, but not for peak acceleration.

Hicks [22] conducted an experiment on eight floors and compared the results with both AISC and $\mathrm{SCl}$ design guides. He concluded that both design guides could estimate the natural frequency accurately, but that the dynamic response for the floor system is usually overestimated. For tested floor systems with relatively low natural frequencies, the predicted acceleration from both design guides is approximately $30 \%$ higher than the experimental one, and this difference varies case by case. Hicks also compared the measured results with the finite element modelling proposed by Willford et al. [40] and found that the difference is widely dispersed, although the average ratio between the two sets of values were 0.98 .

Murray and Boice [30] predicted occupant's perception of vibration according to four different methods: Murray Criterion, Meister Method, SCI 1989 Design Guide, and AISC Design Guide. With the results for 32 buildings, they found that the AISC Design Guide has the most accurate prediction with around $88 \%$ accuracy.
Davis and Murray [13] compared the experimental results for two buildings with the predications of AISC and $\mathrm{SCl}$ design guides (simplified assessment for steel floors). The results show that the AISC Design Guide underestimated the peak acceleration by an average of $20 \%$, which might lead to an unconservative design. Meanwhile, the $\mathrm{SCI}$ Design Guide overestimated the dynamic response by $40 \%$ on average.

\subsection{Summary of literature review}

Substantial research has been conducted to provide a better understanding of the dynamic performance of different floor systems, but there is no unified numerical simulation model pertinent to human-induced floor vibration. Attributed to the complexity involved in the modelling of detailed walking activities, for which it is required to model loads continuously varying in location and time, a certain level of simplification is always adopted for either the structural model or the load model (usually both). The load model used in most studies is short on details, and very few papers focus on the effect of the simplification of the structural and load models on the dynamic response simulation. The most comprehensive load model described in detail is found in publications by Figueiredo et al. [15] and da Silva et al. [11]. One of their load models considered the human-induced load as a moving load. However, they consider neither the overlap time nor the lateral distance between successive footfalls, and only simulated and compared the effect of different load models for one selected walking frequency. To address that research gap, this study focused on the effect of simplification on the dynamic response prediction, which is analysed with three slabs of different thickness, and six load models having different levels of simplification.

\section{Simulation details}

The floor slabs investigated in this study have dimensions of $6000 \times 5000(\mathrm{~mm})$ with three different thicknesses of $100 \mathrm{~mm}, 150 \mathrm{~mm}$ and $200 \mathrm{~mm}$, and are simply supported along two $6000 \mathrm{~mm}$ edges. The slab is made of normal weight concrete having a density $(\rho)$ of $2350 \mathrm{~kg} / \mathrm{m}^{3}$ and a dynamic modulus of elasticity $(E)$ of $38 \mathrm{kN} / \mathrm{mm}^{2}$. Both follow the recommendations in SCI P354 (2009). The slab is assumed to be used for an office building, corresponding to a total external load of $4.84 \mathrm{kN} / \mathrm{m}^{2}$. The linear timedomain model analysis is adopted in this study and the developed computational model for dynamic analysis is shown in Fig. 4. The slab was modelled by the four-node shell element 181, as shown in Fig. 5, which has six degrees 
Fig. 4 Finite element model of the slab (no. of elements is $18,750)$
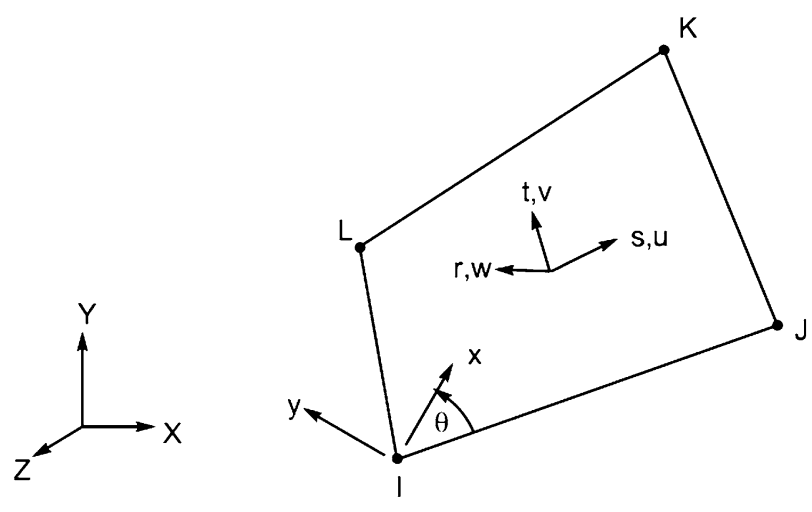

Fig. 5 Shell element 181 [27]

of freedom per node associated with translations and rotations in space (see also [27].

A viscous damping ratio of $\xi$, equal to $3 \%$, was used in the simulations to represent normal use of a fully fitted out and furnished floor condition, as recommended by the SCI Design Guide (2009). The classical viscous damping can be defined as a linear combination of mass-proportional damping and stiffness-proportional damping, known as Rayleigh damping ([10]: 234): $c=\alpha_{0} M+\beta_{0} K$

where $M$ and $K$ are system mass and damping matrices, respectively; $\alpha_{0}$ and $\beta_{0}$ are both constants.

Therefore, the damping ratio $\xi_{n}$ for the $n$-th mode of vibration is:

$\xi_{n}=\frac{\alpha_{0}}{2} \frac{1}{\omega_{n}}+\frac{\beta_{0}}{2} \omega_{n}$

where $\omega_{n}$ is the natural circular frequency corresponding to the $n$th mode.

Subsequently, by prescribing the 3\% damping ratio for the 1 st and 2 nd modes, the values of the constants $\alpha_{0}$ and $\beta_{0}$ are determined by:

$\alpha_{0}=\xi \frac{2 \omega_{1} \omega_{2}}{\omega_{1}+\omega_{2}}$

$\beta_{0}=\xi \frac{2}{\omega_{1}+\omega_{2}}$

where $\omega_{1}$ and $\omega_{2}$ are the natural circular frequencies corresponding to the 1 st and 2 nd modes respectively; $\xi$ is the prescribed damping ratio.

Six different load models with different walking conditions and different levels of simplifications were used to investigate the dynamic behaviour of the floor in this 


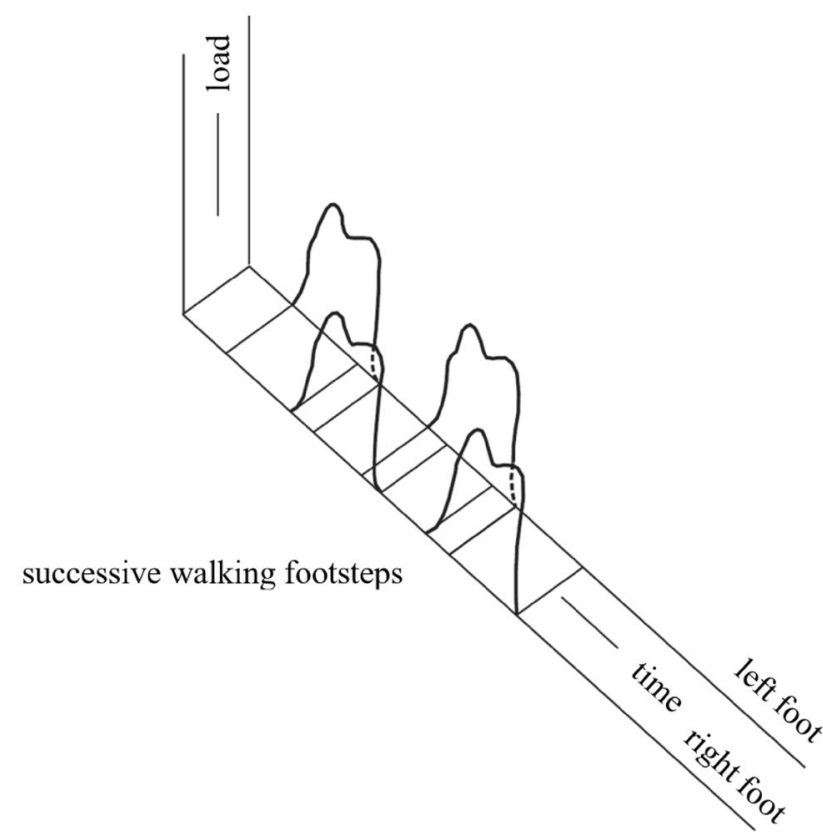

Fig. 6 Typical pattern of running and walking forces [16]

Table 2 Summary of the six load models

\begin{tabular}{llll}
\hline & Load model & $\begin{array}{l}\text { Overlap time } \\
\left(t_{s}-1 / f_{s}\right)\end{array}$ & $\begin{array}{l}\text { Lateral } \\
\text { distance } \\
(0.2 \mathrm{~m})\end{array}$ \\
\hline $\begin{array}{l}\text { Fixed at the } \\
\text { centre of the } \\
\text { slab }\end{array}$ & LM-1-1 & $\bigotimes$ & $\bigotimes$ \\
& LM-1-2 & $\square$ & $\square$ \\
$\begin{array}{l}\text { Walking along } \\
\text { the middle } \\
\text { line }\end{array}$ & LM-2-1 & $\square$ & $\square$ \\
& LM-2-2 & $\square$ & $\square$ \\
& LM-2-3 & $\square$ & $\square$ \\
\hline
\end{tabular}

囚Indicates not considered

$\checkmark$ Indicates considered

study. The six load models were separated into two types of walking activities, the first one is walking at a fixed location at the centre of the slab (denoted by LM-1-n) and the second one is walking along the middle line of the slab (denoted by LM-2-n). Three different levels of details were simulated for each of the aforementioned two walking activities: load model without considering both overlap and lateral distance between successive footfall (denoted by LM-n-1); load model considering the overlap but not the lateral distance between successive footfall (denoted by LM-n-2); and the most realistic load model considering both overlap and lateral distance $(0.2 \mathrm{~m})$ between successive footfall (denoted by LM-n-3), which is based on the typical pattern of walking force suggested by Galbraith and Barton [16] as shown in Fig. 6. A summary of the six load models is provided in Table 2 .

The load induced by a single footfall was applied to the structure through a pressure distributed to nodes within a circle of $0.1 \mathrm{~m}$ diameter. Compared with conventional concentrated loads used in previous research, this method avoids excessive local deformation and the strict requirement that there must be a node located exactly at each footprint (Fig. 8).

Figure 7 illustrates the main steps involved in the FEM simulation. Firstly, several parameters are determined based on the equation introduced in Sect. 2 , including the duration of one step, walking speed, length of steps, and walking loads. The FEM models are then generated for the three slabs, and the locations for each footfall are ascertained for different load models. Finally, the walking loads are applied to those predetermined locations to obtain the slabs' response. For instance, the first three footfalls simulated with LM-2-3 are illustrated in Fig. 8, where both the overlap time and the lateral distance were considered in this load model.

\section{Simulation results and discussion}

The dynamic responses of the floor slab subjected to the excitation caused by human walking were determined through a series of numerical simulations using ANSYS software. As the mode shapes of three slabs are similar, only the first six modes of vibration for the slab with a thickness of $150 \mathrm{~mm}$ are presented in Fig. 9. It can be clearly observed that the mode shape associated with the fundamental frequency is dominated by flexural deformation, which may be regarded as a simply supported beam (one-way slab) in this circumstance. According to the simplified method proposed by SCl guide (2009), the fundamental frequency for a simply supported beam subjected to a uniformly distributed load can be estimated as:

$f=\frac{17.8}{\sqrt{\delta}} \approx \frac{18}{\sqrt{\delta}}$

where $f$ is the natural fundamental cyclic frequency (in $\mathrm{Hz}$ ); $\delta$ is the maximum displacement (in $\mathrm{mm}$ ), and it can be calculated as

$\delta=\frac{5 \mathrm{mgL}^{4}}{384 E \mathrm{I}}=6.32 \mathrm{~mm}$ 
Fig. 7 Main steps of the simulation

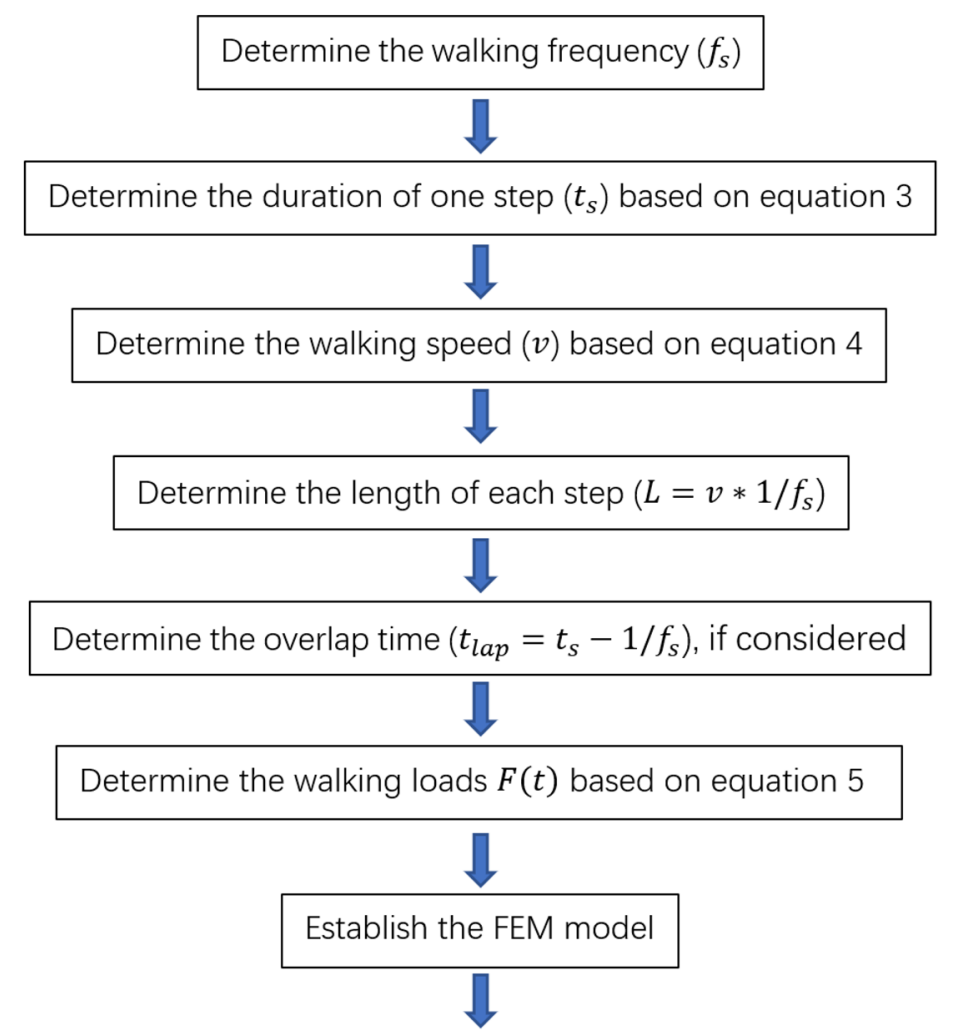

Apply walking loads at predetermined locations according to different load models

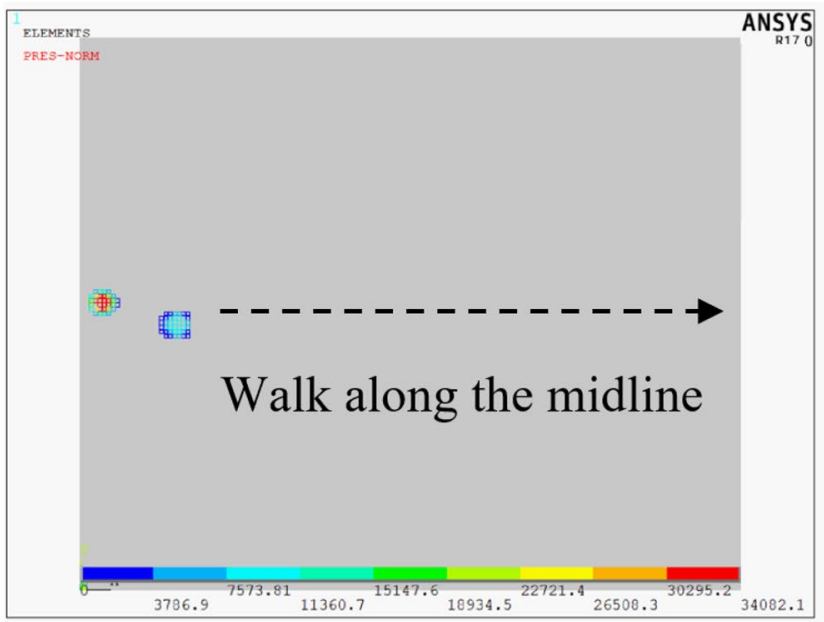

Fig. 8 First three footfalls using LM-2-3

where $I$ is the second moment of inertia equal to $\frac{6 \times 0.15^{3}}{12}=1.6875 \times 10^{-3} \mathrm{~m}^{4} ; L$ is the span equals $5 \mathrm{~m}$.

Hence, the estimated natural fundamental cyclic frequency for the slab with a thickness of $150 \mathrm{~mm}$ is $f=\frac{18}{\sqrt{6.32}}=7.16 \mathrm{~Hz}$, which is slightly lower than the result obtained from the FEM analysis $\left(f_{1}=7.229 \mathrm{~Hz}\right)$. This is

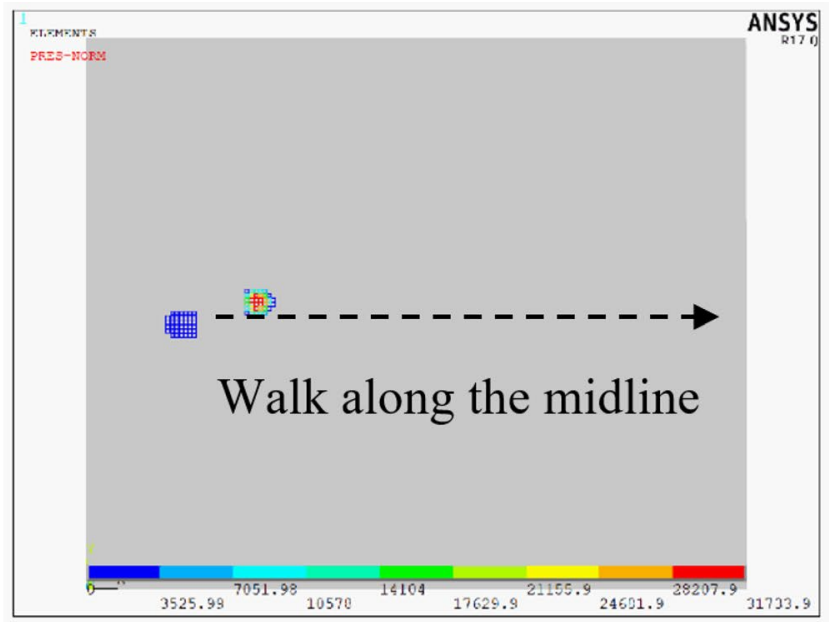

because in FEM finite degrees of freedoms are used for analysis. In other words, some degrees of freedoms are constrained in the FEM model compared with the actual structure with infinite degrees of freedom. In this sense, the FEM model is stiffer than the actual structure model, with the consequence of a slightly higher value of fundamental frequency in FEM. However, for higher-order 
Fig. 9 The first six mode shapes of the slab with a thickness of $150 \mathrm{~mm}$

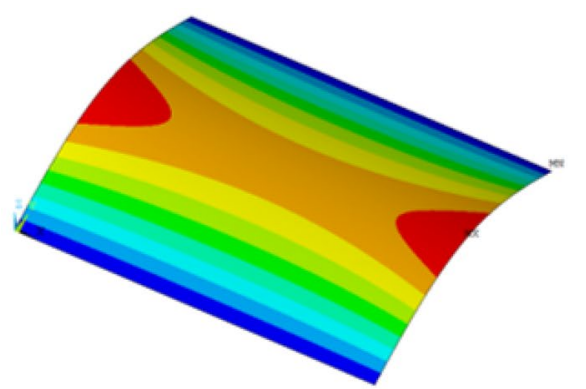

$1^{\text {st }}$ mode shape $f_{1}=7.229 \mathrm{~Hz}$

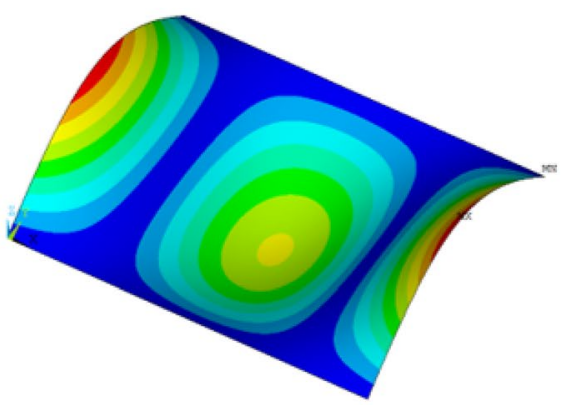

$3^{\text {rd }}$ mode shape $f_{3}=21.517 \mathrm{~Hz}$

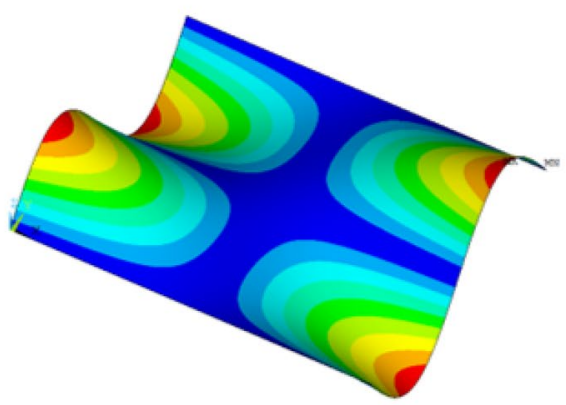

$5^{\text {th }}$ mode shape $f_{5}=32.947 \mathrm{~Hz}$

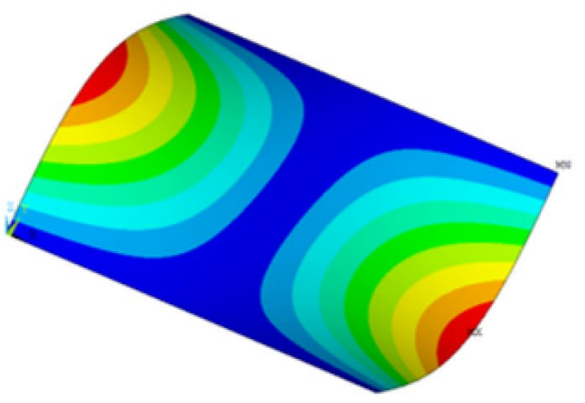

$2^{\text {nd }}$ mode shape $f_{2}=10.682 \mathrm{~Hz}$

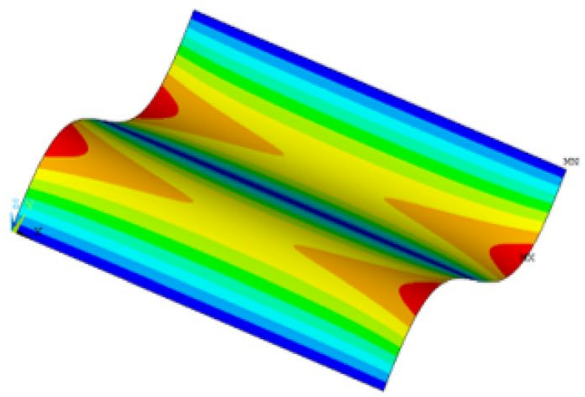

$4^{\text {th }}$ mode shape $f_{4}=29.060 \mathrm{~Hz}$

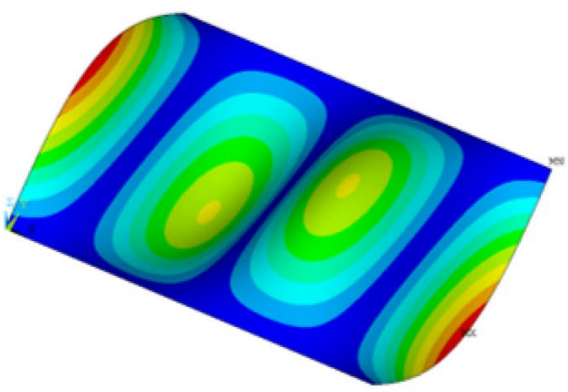

$6^{\text {th }}$ mode shape $f_{6}=41.305 \mathrm{~Hz}$
Table 3 Summary of natural frequencies for three slabs

\begin{tabular}{lllllll}
\hline & 1st & 2nd & 3rd & 4th & 5th & 6th \\
\hline $100 \mathrm{~mm}$ & 4.826 & 7.168 & 14.466 & 19.450 & 22.109 & 27.782 \\
$150 \mathrm{~mm}$ & 7.229 & 10.682 & 21.517 & 29.060 & 32.947 & 41.305 \\
$200 \mathrm{~mm}$ & 9.623 & 14.143 & 28.424 & 38.541 & 43.581 & 54.497 \\
\hline
\end{tabular}

modes, the torsional effect becomes non-negligible, and no simplified approach is available for hand calculations.

The natural frequencies of the first six modes of vibration for three slabs are summarised below (Table 3).

The acceleration histories at the centre of the slabs were recorded for this study. For the slab with a thickness of $150 \mathrm{~mm}$, Figs. 10 and 11 show that the acceleration (peak value/RMS value) of this slab (at the centre) reaches a local peak value at $1.8 \mathrm{~Hz}$, which is approximately equal to the fundamental frequency $(7.2 \mathrm{~Hz})$ divided by 4 . In other words, the first mode responds resonantly to the fourth harmonic of footfall excitation. As the lower harmonic of the footfall load has a higher amplitude [38], it is logical to assume that a more significant resonance effect will occur at the walking frequency of $f_{w}=\frac{f_{1}}{3} \approx 2.4 \mathrm{~Hz}$. However, both the peak acceleration and RMS acceleration keep increasing after $2.4 \mathrm{~Hz}$. This phenomenon is due to the magnitude of human walking loads increasing with the 
Fig. 10 Peak acceleration verse walking frequency (LM-2-3) for the slab with a thickness of $150 \mathrm{~mm}$

Fig. 11 RMS acceleration verse walking frequency (LM-2-3) for the slab with a thickness of $150 \mathrm{~mm}$
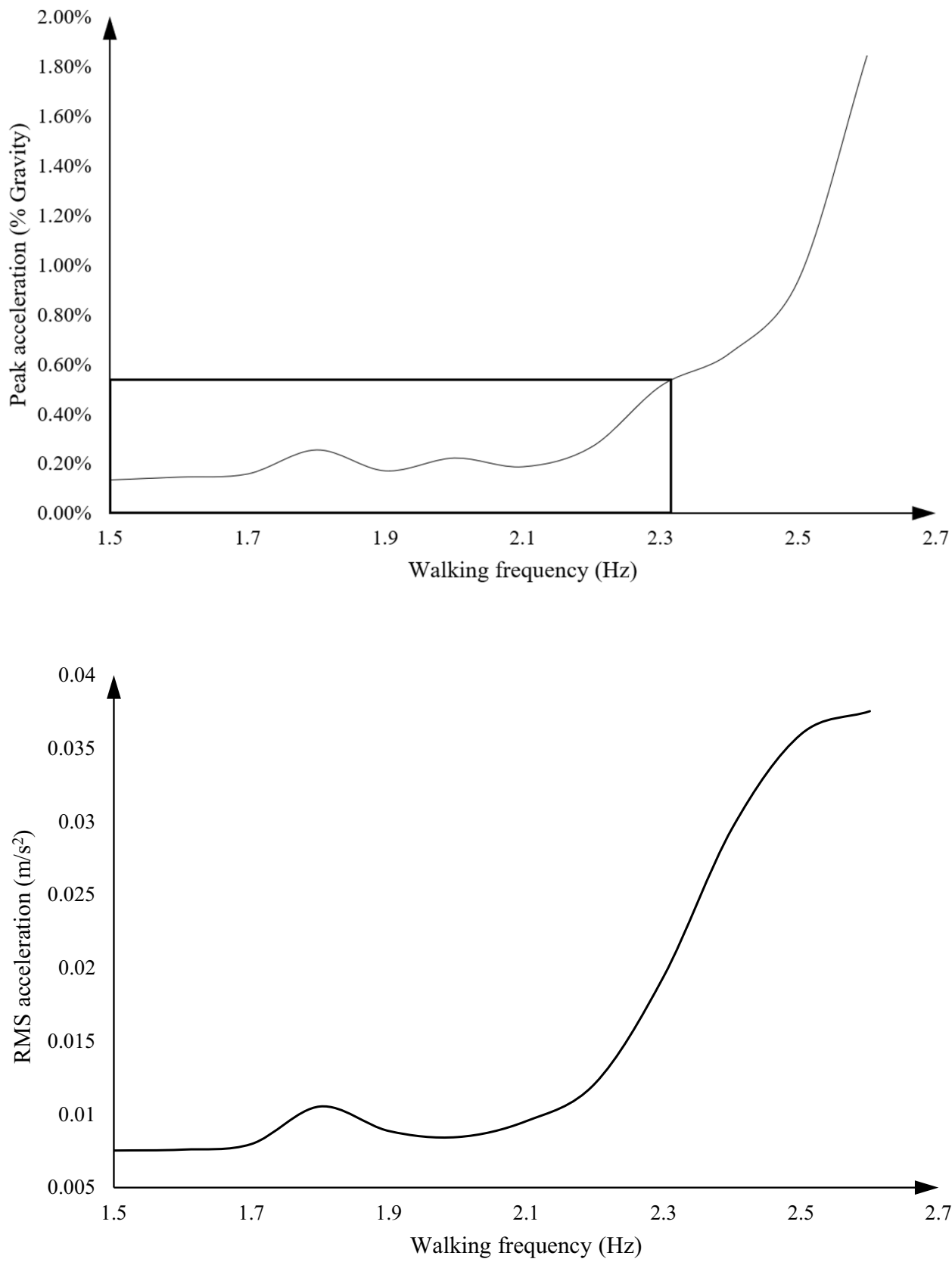

walking frequency, and this could become a dominant factor, especially at high walking frequencies. To be specific, the walking frequency corresponding to the local peak response would be shifted to a higher value. The acceleration histories for $2.4,2.5$, and $2.6 \mathrm{~Hz}$ walking frequencies (for a slab with a thickness of $150 \mathrm{~mm}$ ) are plotted in Fig. 12 to demonstrate the increase in dynamic response.

Similar conclusions can be obtained from the simulation results of the $100 \mathrm{~mm}$ and $200 \mathrm{~mm}$ slabs. The first seven harmonics for the first three vibration modes of slabs are summarised in Tables 4, 5 and 6, where the potential resonant frequencies are marked in colours. Meanwhile, Figs. 13,14 and 15 present the RMS acceleration verses walking frequencies with different load models. It can be observed that for slabs with thicknesses of $100 \mathrm{~mm}$ and $200 \mathrm{~mm}$, the RMS acceleration reaches local peak values around $2.5 \mathrm{~Hz}$, which is slightly higher than the traditional resonant frequency of $2.4 \mathrm{~Hz}$ highlighted in orange.

It is important to observe that for both fixed and moving excitations, the more realistic LM-1-3 and LM-2-3 are 
Fig. 12 Acceleration histories LM-2-3 with $2.4,2.5$ and $2.6 \mathrm{~Hz}$ walking rate (for the slab with a thickness of $150 \mathrm{~mm}$ )
Table 4 First seven harmonics for the first three modes of vibration (for the slab with a thickness of $100 \mathrm{~mm}$ )

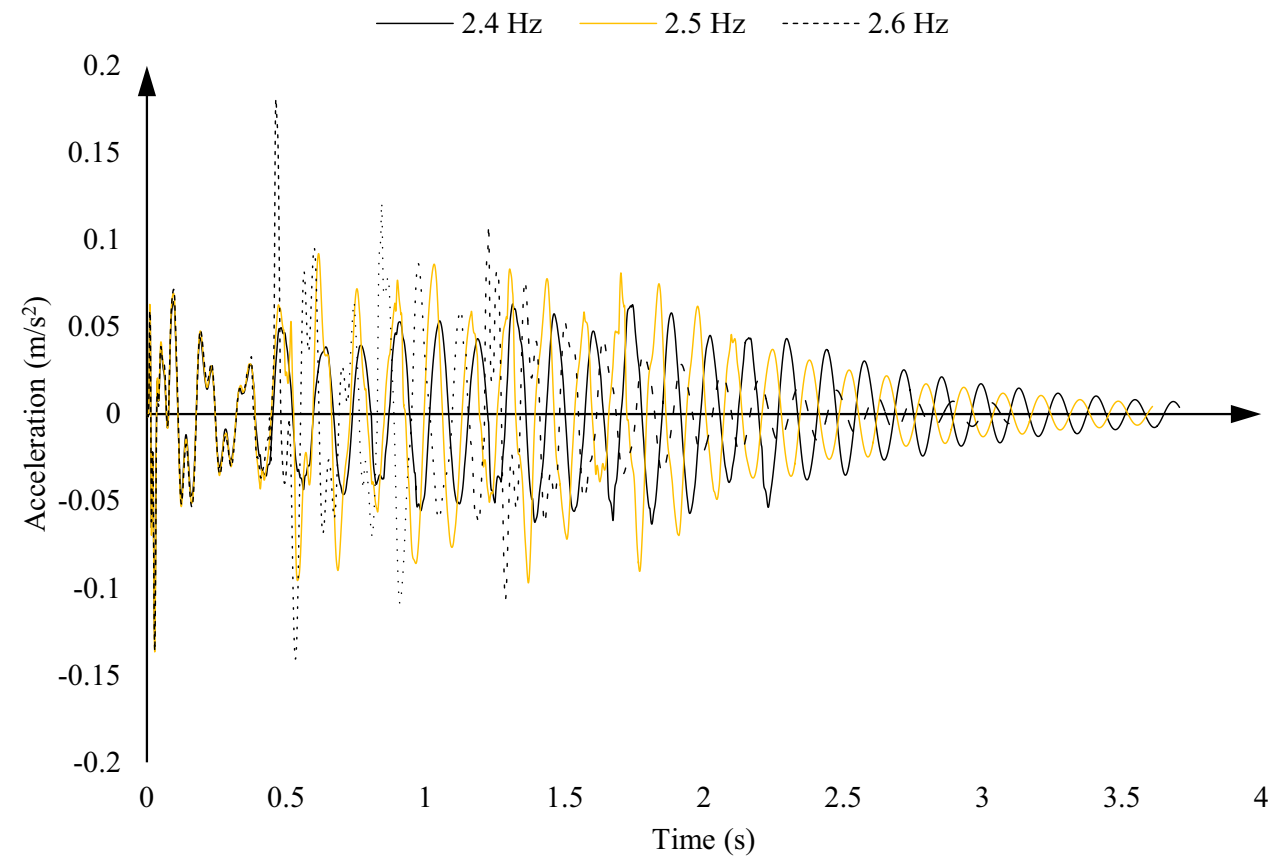

\begin{tabular}{llllllll}
\hline & \multicolumn{7}{l}{$n$ nth harmonic } \\
\cline { 2 - 8 } & 1st & 2nd & 3rd & 4th & 5th & 6th & 7th \\
\hline 1st mode & 4.826 & $\mathbf{2 . 4 1 3}$ & $\mathbf{1 . 6 0 9}$ & 1.206 & 0.965 & 0.804 & 0.689 \\
2nd mode & 7.168 & 3.584 & $\mathbf{2 . 3 8 9}$ & $\mathbf{1 . 7 9 2}$ & 1.434 & 1.195 & 1.024 \\
3rd mode & 14.466 & 7.233 & 4.822 & 3.617 & 2.893 & $\mathbf{2 . 4 1 1}$ & $\mathbf{2 . 0 6 7}$ \\
\hline
\end{tabular}

The bold numbers refer to the frequencies within the normal walking ranges that would cause resonance

\begin{tabular}{llllllll}
\hline & \multicolumn{1}{l}{ nth harmonic } & & & & \\
\cline { 2 - 8 } & 1st & 2nd & 3rd & 4th & 5th & 6th & 7th \\
\hline 1st mode & 7.229 & 3.615 & $\mathbf{2 . 4 1 0}$ & $\mathbf{1 . 8 0 7}$ & 1.446 & 1.205 & 1.033 \\
2nd mode & 10.682 & 5.341 & 3.561 & 2.671 & $\mathbf{2 . 1 3 6}$ & $\mathbf{1 . 7 8 0}$ & $\mathbf{1 . 5 2 6}$ \\
3rd mode & 21.517 & 10.759 & 7.172 & 5.379 & 4.303 & 3.586 & 3.074 \\
\hline
\end{tabular}

The bold numbers refer to the frequencies within the normal walking ranges that would cause resonance

\begin{tabular}{lcclllll}
\hline & \multicolumn{7}{l}{ nth harmonic } \\
\cline { 2 - 8 } & 1st & 2nd & 3rd & 4th & 5th & 6th & 7th \\
\hline 1st mode & 9.623 & 4.812 & 3.208 & $\mathbf{2 . 4 0 6}$ & $\mathbf{1 . 9 2 5}$ & $\mathbf{1 . 6 0 4}$ & 1.375 \\
2nd mode & 14.143 & 7.072 & 4.714 & 3.536 & 2.829 & $\mathbf{2 . 3 5 7}$ & $\mathbf{2 . 0 2 0}$ \\
3rd mode & 28.424 & 14.212 & 9.475 & 7.106 & 5.685 & 4.737 & 4.061 \\
\hline
\end{tabular}

The bold numbers refer to the frequencies within the normal walking ranges that would cause resonance 
Fig. 13 RMS acceleration for the six load models (for the slab with a thickness of $100 \mathrm{~mm}$ )

Fig. 14 RMS acceleration for the six load models (for the slab with a thickness of $150 \mathrm{~mm}$ )
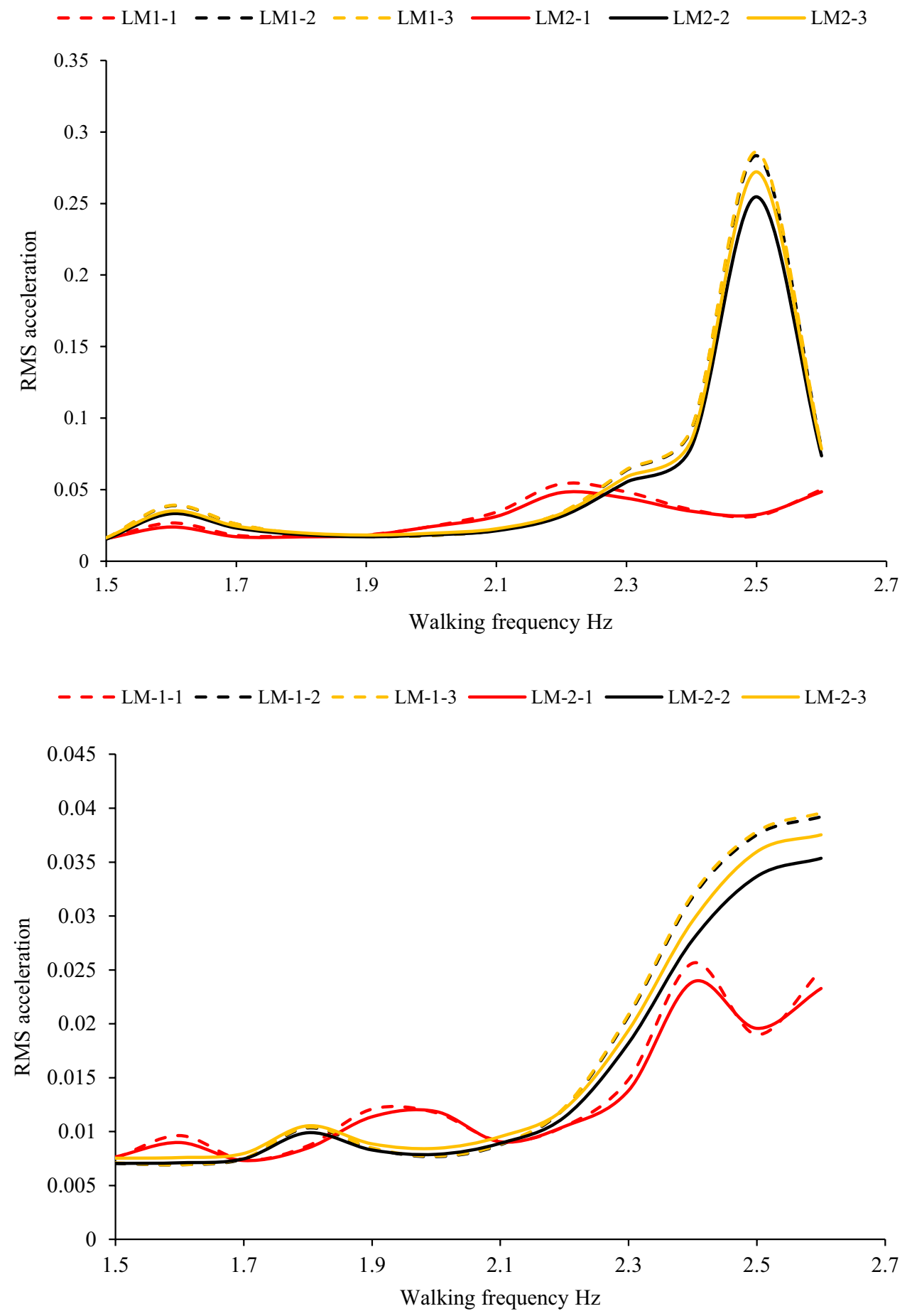

always higher than LM-1-2 and LM-2-2 (not considering the lateral distance); the differences are about $0.72 \%$ and $6.2 \%$ respectively. The acceleration histories for LM-2-2 and LM-2-3 with $2.4 \mathrm{~Hz}$ walking frequency (for a slab with a thickness of $150 \mathrm{~mm}$ ) is plotted in Fig. 16 to provide an intuitive impression of the difference. These differences are too small for humans to perceive. However, where sensitive machines are concerned, the lateral distance may still be worth considering. By contrast, the differences due to the consideration of overlap time are significant and fluctuating. The differences between RMS acceleration of LM-1-1 and LM-1-3 have an average value of $19.6 \%$, with the largest difference of $89.98 \%$. Similarly, the differences between RMS acceleration of LM-2-1 and LM-2-3 have an average value of $18.03 \%$, with the largest difference of $88.07 \%$. Therefore, ignoring the overlap time could lead to an inaccurate and nonconservative estimation of the floor vibration. 
Fig. 15 RMS acceleration for the six load models (for the slab with a thickness of $200 \mathrm{~mm}$ )

Fig. 16 Acceleration histories for LM-2-2 and LM-2-3 with $2.4 \mathrm{~Hz}$ walking rate (for the slab with a thickness of $150 \mathrm{~mm}$ )
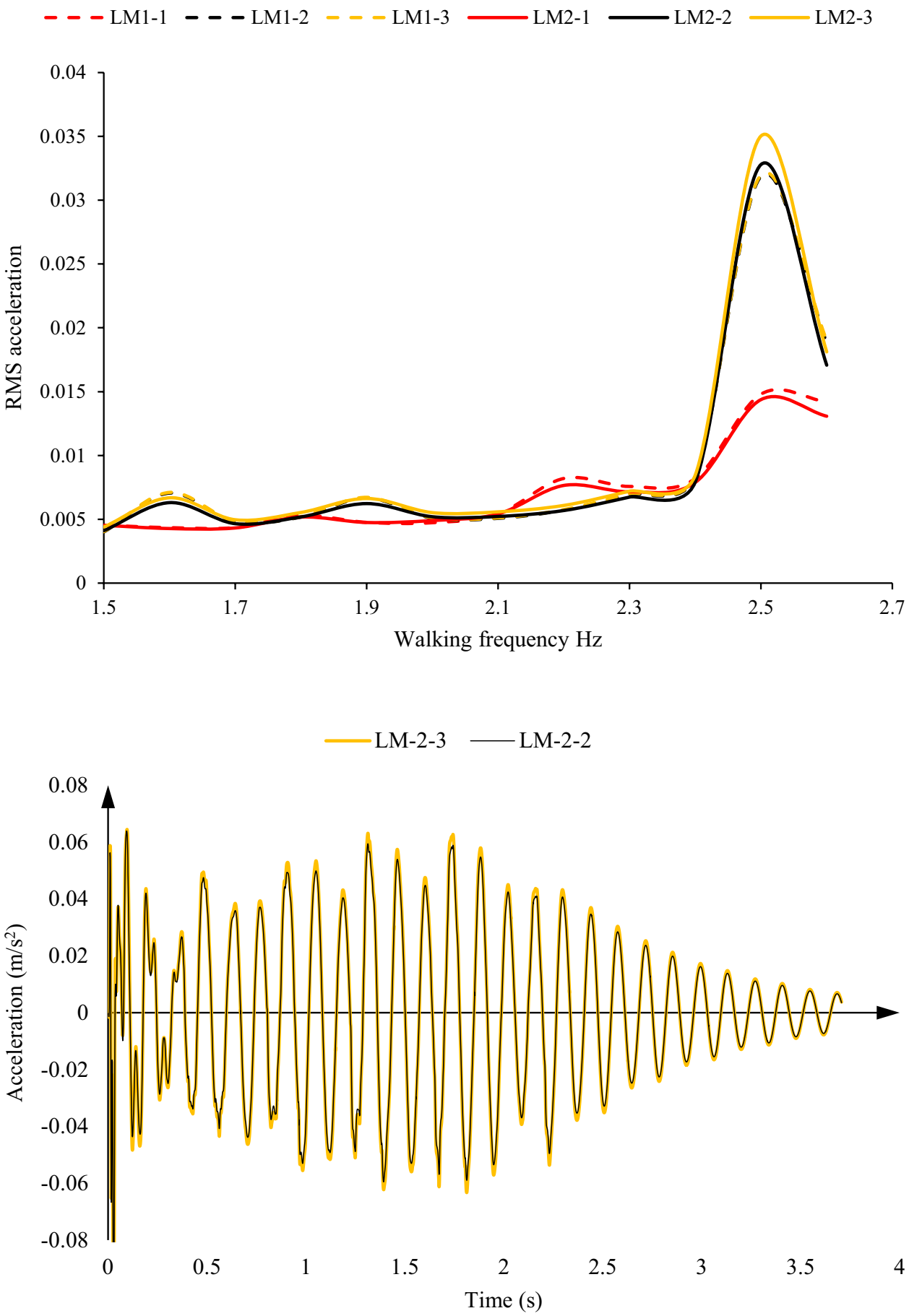

Furthermore, it should be mentioned that when adopting LM-1-n (fixed excitation) to assess the vibration serviceability, it is essential to identify the critical location in the first place. This might be problematic for complex floor plans. However, if the walking path could be known prior to simulation, LM-2-n could capture more realistic dynamic responses of the floor system, although it will induce slightly more difficulties for the simulation. From these discussions, LM-2-2 seems a reasonable load model for the assessment of vibration serviceability of floors (Table 7). 
Table 7 Summary of the main constrains of load models

\begin{tabular}{|c|c|c|c|c|}
\hline & Load model & Overlap time & $\begin{array}{l}\text { Lateral } \\
\text { dis- } \\
\text { tance }\end{array}$ & Constrains \\
\hline \multirow[t]{3}{*}{ Fixed location } & LM-1-1 & $凶$ & $凶$ & $\begin{array}{l}\text { May yield nonconservative results and } \\
\text { need to identify the critical location } \\
\text { first }\end{array}$ \\
\hline & LM-1-2 & $\square$ & $凶$ & Need to identify the critical location first \\
\hline & LM-1-3 & $\square$ & $\square$ & Need to identify the critical location first \\
\hline \multirow[t]{3}{*}{ Along the walking path } & LM-2-1 & $凶$ & $凶$ & $\begin{array}{l}\text { May yield nonconservative results and } \\
\text { more complexity for simulation }\end{array}$ \\
\hline & LM-2-2 & $\square$ & $凶$ & More complexity for simulation \\
\hline & LM-2-3 & $\nabla$ & $\square$ & More complexity for simulation \\
\hline
\end{tabular}

\section{Conclusions}

Extensive FEM modelling was conducted to investigate the dynamic response of three slabs of different thickness to six load models. The following are the study's conclusions.

- The effect of overlapping time between the adjacent footfalls should be included in assessing the floor vibration induced by human walking. To do otherwise would lead to nonconservative results. It is therefore not recommended to use LM-1-n for simulation.

- The critical walking frequency might be higher than the conventional resonant frequency, considering that the human-induced load would increase with walking frequency.

- The lateral distance between successive footfalls may be neglectable for the modelling of human-induced vibration. In other words, LM-2-n could provide enough accuracy, and it is not necessary to consider more complex load models such as LM-3-n.

As a result of these conclusions, it is highly recommended to consider the overlapping time between footfalls when simulating human-induced vibration, which is not usually the case in engineering practices or research literature. The conclusions suggest that the LM-2-2 is a reasonable load model for the assessment of vibration serviceability of floors.

Further research will focus on laboratory experiments to reproduce the six load modes, with resulting data used to compare with the simulation results.

Acknowledgements The authors are grateful for funding support from XJTLU (RDF-14-02-44, RDF-15-01-38, RDF-18-01-23 and PGRS1906002). The support from the Key Program Special Fund in XJTLU (Grant No: KSF-E-19) is also greatly appreciated.

\section{Compliance with ethical standards}

Conflict of interest The authors declare no conflict of interest.

\section{References}

1. Abdeljaber O, Hussein M, Avci O, Davis B, Reynolds P (2019) A novel video-vibration monitoring system for walking pattern identification on floors. Adv Eng Softw 139:102710

2. Ahmadi E, Caprani C, Živanović S (2018) Vertical ground reaction forces on rigid and vibrating surfaces for vibration serviceability assessment of structures. Eng Struct 172:723-738

3. AISC/CISC steel design guide series no. 11 (1997) Floor vibrations due to human activity

4. Allen DE, Murray TM (1992) Design criterion for vibrations due to walking. ASCE J Struct Eng 4:117-129

5. Alvis SR (2001) An experimental and analytical investigation of floor vibrations [MS thesis]. Virginia Polytechnic Institute and State University

6. Bachmann H, Ammann W (1987) Vibrations in structures induced by man and machines. Can J Civ Eng 15(6):1086-1087

7. Barrett AR (2006) Dynamic testing of in-situ composite floors and evaluation of vibration serviceability using the finite element method [PhD thesis]. Virginia Polytechnic Institute and State University

8. Blanchard J, Davies BL, Smith JW (1977) Design criteria and analysis for dynamic loading of footbridges. Proc Symp Dyn Behav Bridges Transp Road Res Lab 18:90-106

9. BS 6472:1992 (1992) Guide to evaluation of human exposure to vibration in buildings $(1-80 \mathrm{~Hz})$

10. Clough RW, Penzien J (1993) Dynamics of structures. McGrawHill, Berkeley

11. da Silva JGS, Vellasco PDS, deAndrade SAL, deLima LR, Figueiredo FP (2007) Vibration analysis of footbridges due to vertical human loads. Comput Struct 85(21-22):1693-1703

12. Dallard P, Fitzpatrick T, Flint A (2001) London millennium bridge: pedestrian-induced lateral vibration. J Bridge Eng 6(6):412-417

13. Davis DB, Murray TM (2007) Vibration tests of Consolidated Systems, Inc. $30 \mathrm{ft}$ Deep-Dek Composite Slab Floor. Blacksburg, Virginia, Virginia Polytechnic Institute and State University, Report No. CEE/VPI-ST07/01

14. de-Juan A, Garcia P, Fernandez del Rincon A (2016) Analysis of human-induced vibrations in a lightweight framework. Appl Acoust 108:19-25 
15. Figueiredo FP, da Silva JG, de Lima LR, de Andrade SA, Vellasco PD (2008) A parametric study of composite footbridges under pedestrian walking loads. Eng Struct 30(3):605-615

16. Galbraith FW, Barton MV (1970) Ground loading from footsteps. J Acoust Soc Am 48(5B):1288-1292

17. GB 50010-2010 (2015) Code for design of concrete structures

18. Guo T, Cao Z, Zhang Z (2019) Frequency domain-based analysis of floor vibrations using the dynamic stiffness matrix method. J Vib Control 25(4):763-776

19. Harper FC, Warlow WJ, Clarke BL (1961) The forces applied to the floor by the foot in walking. Wear 4(6):495-497

20. Harper FC (1962) The mechanics of walking. Res Appl Ind 15(1):23-28

21. Hassanieh A, Chiniforush AA, Valipour HR, Bradford MA (2019) Vibration behaviour of steel-timber composite floors, part (2): evaluation of human-induced vibrations. J Construct Steel Res 158:156-170

22. Hicks S (2004) Vibration characteristics of steel-concrete composite floor systems. Prog Struct Eng Mater 6:21-38

23. Homb A, Kolstad ST (2018) Evaluation of floor vibration properties using measurements and calculations. Eng Struct 175:168-176

24. ISO 10137:2007 (2007) Bases for design of structures-serviceability of buildings and walkways against vibration

25. ISO 2631-1 (1997) Mechanical vibration and shock: evaluation of human exposure to whole-body vibration: part 1-general requirements

26. Jia BY, Yu XL, Yan QS (2017) Model for the lateral vibration of footbridge under the parametric resonance stochastic framework. J Vib Eng Technol 5(5):477-485

27. Madenci E, Guven I (2015) The finite element method and applications in engineering using ANSYS. Springer, New York

28. Mendes JP, da Silva JGS, Varela WD (2016) Numerical simulation of a vibration control system to attenuate the dynamic response of composite footbridges when submitted to human walking. J Vib Eng Technol 4(3):221-234

29. Mohammed AS, Pavic A (2017) Effect of walking people on dynamic properties of floors. Procedia Eng 199:2856-2863

30. Murray TM, Boice MD (2003) How accurate are current floor vibration procedures? In: North American Steel Conference Proceedings, AISC, Chicago, Illinois
31. NBCC 2005 (2005) Structural commentaries-commentary D: deflection and vibration criteria for serviceability and fatigue limit states

32. Nguyen TH, Saidi I, Gad EF (2012) Performance of distributed multiple viscoelastic tuned mass dampers for floor vibration applications. Adv Struct Eng 15(3):547-562

33. Pavic A (1999) Vibration serviceability of long-span cast in-site concrete floors. PhD Thesis, University of Sheffield, UK

34. Piszczek K (1958) The possibility of dynamic stability loss under moving concentrated loads. Arch Mech Stosow 10(2):195-210

35. Rasmussen G (1983) Human body vibration exposure and its measurements. J Acoust Soc Am 73:2229

36. Sedlacek G, Heinemeyer C, Butz C (2006) Generalisation of criteria for floor vibrations for industrial, office, residential and public building and gymnasium halls. European Commission, Luxembourg

37. Sladki MJ (1999) Prediction of floor vibration response using the finite element method [MS thesis]. Virginia Polytechnic Institute and State University

38. Smith AL, Hicks SJ, Devine PJ (2009) Design of floors for vibration: a new approach. The Steel Construction Institute, Berkshire

39. VDI 2057 Part 1 (2015) Human exposure to mechanical vibrations: whole-body vibration

40. Willford M, Field C, Young P (2006) Improved methodologies for the prediction of footfall-induced vibration. In: Proceedings of the 2006 architectural engineering national conference, ASCE, Reston, Virginia

41. $\mathrm{Xu} \mathrm{L}$ (2011) Floor vibration in lightweight cold-formed steel framing. Adv Struct Eng 14(4):659-672

42. Young P (2001) Improved floor vibration prediction methodologies. In: Proceedings of Arup vibration seminar on engineering for structural vibration-current developments in research and practice, Institution of Mechanical Engineers, London, UK

43. Zheng J, Wang J (2012) Generalization of Dunkerley's equation for the undamped linear positive semidefinite system. Procedia Eng 31:403-408

Publisher's Note Springer Nature remains neutral with regard to jurisdictional claims in published maps and institutional affiliations. 